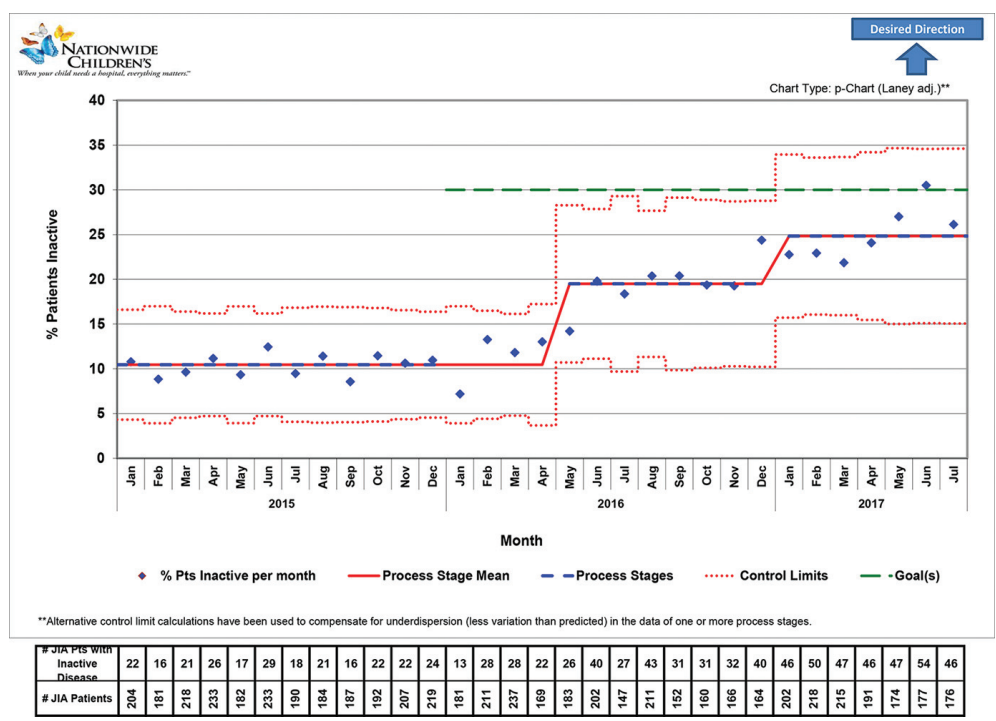

Abstract 904 Figure $1 \%$ JIA patients with inactive disease

\section{ACHIEVING INACTIVE DISEASE IN JUVENILE IDIOPATHIC ARTHRITIS PATIENTS}

Stephanie Lemle, Cagri Toruner, Stacy Ardoin, Ed Oberle, Vidya Sivaraman, Aliese Sarkissian, Bethanne Thomas, Karla Jones. Nationwide Children's hospital, US

\subsection{6/bmjoq-2017-IHI.10}

Background Nearly 300000 children in the US with Juvenile Idiopathic Arthritis (JIA) suffer from chronic pain, swelling and stiffness of joints, which impact their quality of life. Appropriate and aggressive treatment can minimise symptoms and slow further damage to joints, preserving function and agility.

Objectives To increase the percentage of patients who presenting to clinic with inactive disease from $11 \%$ in 2015 to $30 \%$ by December of 2017 .

Methods A KDD was used to identify barriers and to develop disease management strategies. The most effective interventions were initially centred around educating parents and patients on disease management, pre-visit planning and provider data entry. These interventions led to the first statistical shift. Next, providers worked through Patient Global Assessment (PGA) and population management exercises. This standardised disease activity level scoring and allowed providers to challenge each other regarding optimal care of patients. This led to the second statistical shift.

Results During the baseline period (January 2015-May 2016), only $11 \%$ of over 3000 patients were inactive. Disease activity decreased during the remainder of 2016, where 20\% of 1385 patients were inactive $(p$-value $=0.000)$. As population management took effect, another shift in data occurred in January of 2017, resulting in 25\% of 1353 patients have no disease activity ( $p$-value $=0.000)$.

Conclusions These strategies have proven to be successful in improving the disease activity level of patients. Entering a state of inactive disease motivates providers to continue these efforts as their patients' quality of life improves.

\section{OPTIMISING SYSTEM-LEVEL PAEDIATRIC DISCHARGE EFFICIENCY}

Laura Brower, Madsen Nicolas, Smriti Neogi, Cable Rhonda, Lichner Kelli, Debra Chandler, Christine White, Angela Statile. Cincinnati Children's Hospital, US

10.1136/bmjoq-2017-|HI.11

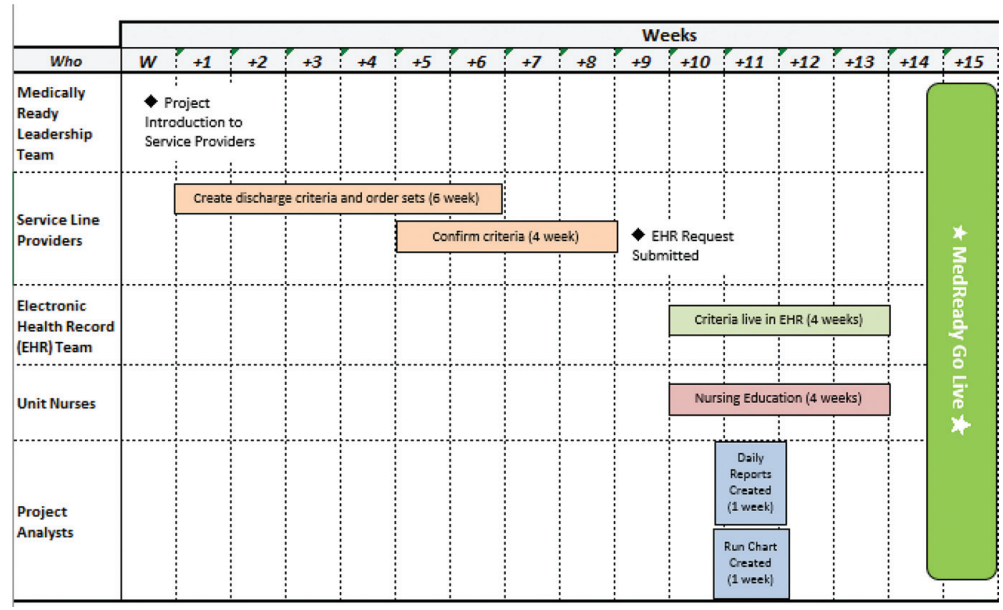

Abstract 911 Figure 1 Implementation timeline 